\title{
Antecedents of intentional and incidental exposure modes on social media and consequences for political participation: a panel study
}

\author{
Andreas Nanz ${ }^{1}$ (D) Raffael Heiss $^{2}$ (D) Jörg Matthes ${ }^{1}$ (D)
}

Accepted: 16 September 2020 / Published online: 26 September 2020

(c) The Author(s) 2020, corrected publication 2020

\begin{abstract}
This study investigates antecedents and consequences of incidental and intentional exposure behavior to political information on social media. Based on the Social Media Political Participation Model (SMPPM), we investigated how political and non-political motivations predict intentional and incidental exposure modes while accounting for moderators (i.e., personal curation skills and the frequency of social media political exposure). We also examined how intentional and incidental exposure modes affect low- and high-effort political participation. We rely on data from a two-wave panel survey based on representative quotas for the Austrian population $(N=559)$ to run autoregressive models. Political information motivation predicted the intentional mode, and this relationship was stronger with rising levels of curation skills. By contrast, entertainment and social interaction motivations increased individuals' incidental exposure mode. The intentional mode led to low-effort political participation but not to high-effort participation. However, the incidental mode was unrelated to both low- and high-effort participation.
\end{abstract}

Keywords Social media $\cdot$ Intentional mode $\cdot$ Incidental mode $\cdot$ Political participation · User motivations

Electronic supplementary material The online version of this article (https://doi.org/10.1057/s4126 9-020-00182-4) contains supplementary material, which is available to authorized users.

Andreas Nanz

andreas.nanz@univie.ac.at

Raffael Heiss

raffael.heiss@mci.edu

Jörg Matthes

joerg.matthes@univie.ac.at

1 University of Vienna, Währinger Straße 29, 1090 Vienna, Austria

2 MCI Innsbruck, Universitätsstraße 15, 6020 Innsbruck, Austria 


\section{Introduction}

In contrast to the politics section of a newspaper, social media (SM) expose people to various topical domains and content types-ranging from entertainment videos to statements by the president-right next to each other. Although political information has become a substantial part of most SM platforms, most users might turn to these platforms for other than informational purposes (Knoll et al. 2020). Researchers have frequently highlighted the possibility of SM to bring political information to politically uninterested citizens (e.g., Matthes et al. 2020; Valeriani and Vaccari 2016). Besides the affordances that allow citizens to seek and consume political information on SM actively, these platforms can thus facilitate incidental exposure.

Despite the relevance of this topic for political communication scholarship, there is hardly any research on the predictors of both, incidental and intentional exposure on social media. Moreover, research in this area hardly formulates a clear-cut distinction between intentional and incidental exposure (Matthes et al. 2020). Although some studies discuss incidental exposure (e.g., Bode 2016; Tang and Lee 2013; Valeriani and Vaccari 2016), the conceptual differences to nonincidental (i.e., intentional) exposure are often not discussed in depth (for notable exceptions, Fletcher and Nielsen 2018; Knoll et al. 2020; Oeldorf-Hirsch 2018). Furthermore, existing studies are almost exclusively based on cross-sectional data (for an exception, Weeks et al. 2017) and rely on the single item question proposed by Tewksbury et al. (2001), which measures the frequency of incidental encounters. However, it remains unclear to what extend the frequency of incidental encounters may be confounded with more active political behaviors or political ties in the network (Heiss and Matthes 2019).

In this study, we seek to advance our understanding about the theoretical distinctions, antecedents, and consequences of the intentional and incidental mode. By relying on the Social Media Political Participation Model (SMPPM; Knoll et al. 2020), we speak of modes of exposure. In the intentional mode of exposure, individuals actively seek political information on SM (e.g., search for and follow political sources) while in the incidental mode of exposure, individuals encounter political information only incidentally (i.e., while browsing for nonpolitical content). What is more, we argue that these two modes of exposure are driven by distinct user motivations and have different participatory outcomes (Knoll et al. 2020).

\section{Intentional and incidental exposure on social media}

Scholars often distinguish between two different pathways in which a citizen encounters political information on SM (e.g., Tang and Lee 2013): intentional and incidental exposure. The former describes a behavioral pattern in which users actively look for political information (e.g., visiting a politician's profile) 
or intentionally configure their SM to encounter political information. In contrast, incidental exposure describes situations in which users stumble upon political information rather than actively search for it. For instance, while browsing their SM for relaxation, citizens might come across sponsored content by politicians, political status updates by social ties, political news, or various other forms of political content inadvertently.

\section{Antecedents of intentional and incidental political exposure}

Existing research suggests that there are different boundary conditions which determine individuals' exposure to political information: motivation, skills, and network characteristics affect opportunities for political exposure (Heiss et al. 2019; Matthes et al. 2020; Thorson and Wells 2016). In general, individuals need to be motivated to seek and engage with political information, they need to be skilled to find and process political information, and they need to have the opportunity structures to encounter political information (Beam et al. 2018).

For both incidental and intentional exposure, the general opportunity to encounter political information is a fundamental prerequisite. While broadcast channels create the opportunity for political exposure by mixing entertainment and political information in their schedules (Krugman and Hartley 1970), SM content is determined by "curated flows" (Thorson and Wells 2016). A diverse set of agents such as journalists, social contacts and strategic communicators influence the content users see on SM and thus their opportunity to encounter political information. However, the influence of these agents may vary as individuals differ in terms of their network characteristics. For example, some individuals may have a high number of politically active ties in their network and are thus exposed to political information regardless of motivations or skills (Tang and Lee 2013).

Similarly, general motivations that drive SM use can affect the amount of opportunities individuals have to encounter political information. These motivations shape the behavior of users on SM and therefore influence the likelihood of encountering political information-Thorson and Wells call this "personal curation" (2016, p. 315). For example, political information needs may affect the likelihood of following a politician or a news organization while entertainment needs may motivate individuals to curate their newsfeed with entertaining but often non-political contents.

It has been argued that individuals also need skills to manage their newsfeed (Correa 2016) in order to customize their content exposure. Users can filter their newsfeed, handpick their network and remove content (i.e., hiding). Despite the technological affordances to tailor one's own SM experience, a substantial share of users does not feel to be in control over the content they see in their newsfeed (Pew Research Center 2018).

\section{Consequences of intentional and incidental political exposure}

Scholars largely agree about the positive effects of intentional exposure to political information (McLeod et al. 1999). People who are motivated to seek political 
information should be more likely to process political information. News consumption's effect on political participation is fostered by activities which involve further processing (McLeod et al. 1999). Multiple studies find a positive effect of using social media for news or political information on political participation (e.g., Gil de Zúñiga et al. 2014).

Before the spread of the Internet, scholars discussed incidental exposure in the light of television viewing (Krugman and Hartley 1970). The mix between entertainment and political information on broadcast TV exposed viewers to both types of content. This notion is challenged by the emergence of high-choice media environments. For example, Prior (2005) argues that "accidental exposure should become less likely in a high-choice environment because greater horizontal diversity (the number of genres available at any particular point in time) increases the chance that viewers will find content that matches their preferences" (p. 579). Thus, people might consume less political information and subsequently participate less due to the amount of non-political choices. Even though there is evidence that incidental exposure may become less relevant in high-choice environments, some research indicates that if individuals are incidentally exposed to political information, this still may have a positive effect on their civic engagement (Valeriani and Vaccari 2016). Thus, others have argued that SM "despite its customizability, acts as a lowchoice media environment” (Bode 2016).

\section{Social Media Political Participation Model (SMPPM)}

In this section, we outline the theoretical pathways proposed by the Social Media Political Participation Model (SMPPM, Knoll et al. 2020) to develop our hypotheses. The SMPPM distinguishes between two paths of exposure: incidental and intentional exposure. Individuals can turn to social media for various political and non-political motivations (e.g., Baek et al. 2011). The motivations are then linked to intentional or mere incidental exposure to politics. In this paper, we distinguish between two modes of exposure (see Heiss et al. 2019). The intentional exposure mode describes a state in which individuals actively look for political information, while the incidental mode refers to a state in which individuals only stumble across political information by accident. The concept of modes is thus different from general user motivations. While general user motivations can explain why individuals turn to SM more generally, exposure modes refer to specific situational behaviors on SM. Finally, the SMPPM also outlines potential participatory effects attributed to the situational modes. Following, we outline these pathways in detail.

\section{Motivations as antecedents of the intentional and incidental exposure modes}

First of all, the SMPPM assumes that individuals' mode of exposure is determined by their user motivations. This assumption rests on the uses and gratifications approach which suggests that needs drive media consumption. For various media, scholars identified a certain set of overarching needs that propel 
consumption: entertainment, information seeking, social interaction, and personal identity (Ruggiero 2000). Because of its functions and sharing possibilities, selfexpression need is often added to the motivations for SM usage (Skoric et al. 2016). Overall, people use SM to pursue different sets of goals and users' gratifications are thus related to specific behavioral patterns (Leiner et al. 2018).

Turning now to political information, the SMPPM argues that individuals' motivations are antecedents of the mode in which users encounter political content. This is especially true in high-choice media environments like SM (Van Aelst et al. 2017), where users can personally curate the content they see. We expect that users translate their political motivation into behavioral patterns in which they actively search and intentionally expose themselves to political information.

H1 Political information motivation will increase the intentional mode.

While we would expect to find the relationship proposed in $\mathrm{H} 1$ for other media types too, $\mathrm{SM}$ is to some extent distinct. Because of its range of functions, users of SM need skills to customize their SM experience in accordance with their motivations. The SMPPM suggests that even though political motivation is a necessary precondition for intentional exposure behavior, personal curation skills may moderate the relationship between motivations and the intentional mode (Knoll et al. 2020; Thorson and Wells 2016). Particularly, if SM is considered as a high-choice media environment, this skill set should help individuals to select the information they want to see. We define personal curation skills as the extent to which users report to have control over their newsfeeds and are hence able to access personally relevant information (see Pew Research Center 2018). Following this reasoning, we hypothesize:

H2 The effect of political information motivation on the intentional mode will become stronger with rising levels of personal curation skills.

According to the SMPPM, the political activity in the network can increase exposure in the network. This may then increase the opportunities for active political information seeking (Beam et al. 2018; Tang and Lee 2013). In fact, even if individuals are motivated to seek political information, this motivation will only be translated into intentional exposure when the environment also encourages such activities. For example, many young individuals may be motivated to engage in political action, but do not know how and where to engage in such activities (Gerodimos 2008; Heiss and Matthes 2016). However, if they are already embedded in a highly active politically environment, they may be more likely to transform their motivation into real action. Following this reasoning, we assume that strong political exposure in the network can boost the effect of user motivation on the intentional mode.

H3 The effect of political information motivation on the intentional mode will be stronger for users with high levels of social media political exposure. 
As mentioned before, people use SM to fulfill more than only informational needs. Despite browsing SM to pursue non-political goals, users may still encounter political information (Valeriani and Vaccari 2016). For example, someone in their network might express a political opinion or share a political post. When users follow non-political motivations, exposure to political information most likely does not align with their most dominant motivation (e.g., entertainment). In other words, the political content does not meet the expectations of individuals who wants to satisfy non-political needs and might be dismissed (see Palmgreen 1984). According to the SMPPM, users pursuing non-political motivations while browsing SM will engage less with political content. Thus, if users stumble upon political information while browsing SM for non-political motivations they will be in the incidental mode of exposure.

H4 Nonpolitical motivation like (a) entertainment, (b) social interaction and (c) self-expression will be positively related to the incidental mode of exposure on social media.

\section{Political participation as goal-directed behavior}

Before discussing the pathways to participation, we briefly turn to political participation as a concept. We follow Brady's definition of political participation as behavior "by ordinary citizens directed towards influencing some political outcomes" (1999, p. 737). In this sense, citizens participate politically to change a status-quo or to stop a status-quo from changing. In other words, activities that count as political participation are means to an end, which leads us to defining political participation as a goal-directed behavior (Kruglanski et al. 2002).

Most contemporary studies in this area rely on a distinction between online and offline forms of political participation (e.g., Gil de Zúñiga et al. 2014). We do not follow this dichotomy. Our main goal is not to explain whether new groups of citizens engage politically because of the new opportunities the online world offers (e.g., Oser et al. 2013). We do not aim to follow this "predominant focus of the e-participation literature on identifying mobilizing effects" (Gibson and Cantijoch 2013, p. 704). Rather we want to explain individual goal-directed behavior, which is by definition contingent on perceived attainability and effort of the activity and not on the specific way (online or offline) used to pursue the goal (see Kruglanski et al. 2002). For example, when defined as goal-directed behavior, a citizen's decision to contact a politician should be primarily driven by the dominance of the goal (e.g., to convince him/her), the cost involved (e.g., time) and the attainability (i.e., probability to succeed) and not by its means (i.e., type of contact; e.g., email or mail). Thus, we argue that it might be more useful to emphasize the effort aspect of political participation than the mere circumstance whether an activity is performed online or offline (Knoll et al. 2020). This might be essentially true if one strives to explain individual-level differences in political participation-as we do in this paper. 


\section{Consequences of the exposure modes for political participation}

According to the SMPPM, the incidental and intentional mode differ in terms of the cognitive effort individuals will use to process political information. The intentional mode increases the likelihood for but must not always lead to effortful processing. For example, a user looking for information about an upcoming local election might not appraise a political post by an acquaintance living on the other side of the world as relevant and therefore will most likely not engage in systematic processing. The SMPPM assumes that those who encounter political information in the intentional mode are more likely to appraise such content as relevant and subsequently are more prone to engage in systematic and effortful processing. In contrast, users who stumble upon political content in the incidental mode will be less likely to appraise political information as relevant and subsequently will rely on less effortful processing.

The SMPPM argues that citizens who appraise political content as relevant are more likely to evaluate the implications of such information and are subsequently more prone to form participatory goals. Furthermore, increased personal importance of information is associated with more effortful processing and more stable attitudes (Blankenship and Wegener 2008). Similarly, increased elaboration of political information, which, for example, is boosted by expressing one's opinion online, can increase attitude strength (Cho et al. 2018). Higher (political) knowledge and attitude strength, in turn, are associated with stronger behavioral reactions (e.g., Johann 2012). Thus, we expect that such effortful processing cannot only increase low-effort participation such as signing an online petition but may also increase high-effort participation like joining a demonstration or forming an online group to pursue a political goal. This is also in line with previous research. Various studies found an association between information seeking activities and political participation in online environments (e.g. Gil de Zúñiga et al. 2014). Although most of these studies do not clearly distinguish between modes of exposure, this line of research supports the assumptions we derived from the SMPPM.

H5 The intentional mode of exposure on social media will be positively related to (a) high-effort and (b) low-effort political participation.

In contrast, users who stumble upon political information on SM in the incidental mode are less likely to appraise the content as relevant. Thus, individuals will often dedicate little attention to political information when they encounter it in the incidental mode. They will opt for low-effort information processing. Therefore, we cannot expect individuals to form strong participatory goals. However, this does not mean that encountering political information in the incidental mode does not affect recipients at all. Previous research suggests that incidental exposure might instigate passive learning (Krugman and Hartley 1970) and possibly fosters political participation (Valeriani and Vaccari 2016). Despite these possible paths to political participation, we expect individuals who are exposed to political information on SM in the incidental mode to invest only a limited amount of effort to pursue participatory goals. 
H6 The incidental mode of exposure on social media will be positively related to low-effort political participation.

\section{Methods}

We conducted a two-wave online survey in the context of the Austrian national election 2017 ( N=559). Survey Sampling International (SSI) recruited the participants. We defined representative quotas for age, gender, and education. The survey company sent our 14,688 invitations of which 953 individuals started the survey $(6.49 \%)$. One hundred eighty individuals did not finish the survey or were screened out because of full quotas. Additionally, we filtered out participants who reported to never use Facebook, Twitter, YouTube or Instagram, respondents above the age of 65 , and eight respondents with extraordinary long or short response times. We collected data from $N=764$ completed questionnaires in the first wave and some $73 \%$ of these individuals responded in the second wave. The sample is composed of $50.27 \%$ female. Nineteen percent had college degrees, $27 \%$ had degrees from college-bound high schools, and $48 \%$ apprenticeship or vocational schools. The remaining participants hold degrees from compulsory schools. Participants were between 16 and 65 years old $(M=44.49, S D=12.61)$. The first wave was conducted between the 29th of August and the 2nd of September 2017. The second wave was implemented one week before the election. Data were collected between October 5 and October 12. The election took place on October 15.

\section{Measures}

If not stated otherwise, the items below were measured on a 7-point agreement scale (i.e., $1=$ disagree, $7=$ agree). We calculated mean scales for variables with multiple questionnaire items. Motivations, moderators, and control variables were measured in the first wave while data for participation and exposure modes were collected in both waves.

\section{Motivations}

Items were derived from previous studies investigating motivations for Internet and SM use (Ancu and Cozma 2009; Baek et al. 2011; Kaye and Johnson 2004). For each item, participants indicated their level of agreement. Political information motivation ( $\alpha=.95, M=3.06, \mathrm{SD}=1.79$ ) was measured with four items, asking participants why they use SM. The items included: (1) to get information on political issues, (2) to follow current political events, (3) to learn about interesting political perspectives, and (4) to see how people from my network think about political issues. Three items measured entertainment motivation $(\alpha=.82, M=4.06, \mathrm{SD}=1.64)$, asking participants whether they use SM (1) to pass time, (2) to find entertaining information, and (3) to watch entertaining videos or pictures. Social interaction motivation $(\alpha=.91, M=3.71, \mathrm{SD}=1.88)$ was measured as whether participants use SM (1) 
to stay in contact with other people, (2) to show other people that they care about them, and (3) to maintain existing friendships. Finally, self-expression motivation $(\alpha=.92, M=2.72, \mathrm{SD}=1.66)$ was measured as whether participants use SM (1) to express their interests to others, (2) to show others what they are doing, and (3) to post pictures, videos and updates.

\section{Mode of exposure}

We used the scales proposed by Heiss et al. (2019). We measured exposure modes by asking respondents about ways in which they "encounter political information on social media". Three items for the incidental exposure mode $\left(\alpha_{(\mathrm{t} 1)}=.83, M=3.68\right.$, $\left.\mathrm{SD}=1.81 ; \alpha_{(\mathrm{t} 2)}=.83, M=3.70, \mathrm{SD}=1.85\right)$ asked whether respondents (1) stumble upon news only by accident, (2) only see political posts when other people from their network post about politics, and (3) do not seek political information, but sometimes see political information by accident. Intentional exposure mode $\left.\alpha_{(\mathrm{w} 1)}=.88, M=2.32, \mathrm{SD}=1.59 ; \alpha_{(\mathrm{w} 2)}=.88, M_{(\mathrm{w} 2)}=2.18, \mathrm{SD}_{(\mathrm{w} 2)}=1.58\right)$ was measured as whether participants (1) actively search for political information, (2) follow political information sources, and (3) take care of seeing political information on their newsfeed.

Furthermore, we tested whether our measures for the intentional mode, incidental mode and political information motivation are distinct from each other. We found a three factor solution using parallel analysis and principal axis factoring with oblimin rotation (Carpenter 2018; Worthington and Whittaker 2006). All factor loadings were above 0.69 and all eigenvalues were above 1.8 (details available in the online supplementary document).

\section{Political participation}

To measure high-effort participation $\left(M_{(\mathrm{t} 1)}=0.52, S D_{(\mathrm{t} 1)}=1.02 ; \quad M_{(\mathrm{t} 2)}=0.48\right.$, $\left.S D_{(\mathrm{t} 2)}=1.03\right)$ participants were asked whether they performed the following activities during the last month (yes/no): (1) writing a longer political comment online (e.g., Facebook message, Email, Blog entry) to convince others with their arguments, (2) contacting a politician or journalist via Email or SM to increase awareness of political issues (3) creating a political group online (e.g., WhatsApp, Facebook) in order to increase awareness of political issues, (4) taking part in a demonstration or protest related to a political issue, (5) taking part in a political assembly to discuss political topics (e.g., community or school assembly), (6) working for a political organization (political party, NGO, school organization). Low-effort participation $\left(M_{(\mathrm{t} 1)}=1.39, \mathrm{SD}_{(\mathrm{t} 1)}=1.63 ; M_{(\mathrm{t} 2)}=1.31, \mathrm{SD}_{(\mathrm{t} 2)}=1.62\right)$ was measured by asking participants whether they performed the following six activities during the last month: (1) liking or sharing a political post on SM, (2) adding a short comment to a political post on SM, (3) signing an online petition related to a political issue, (4) reminding others of a political event or engagement opportunity (e.g., voting, signing a petition etc.), (5) using a campaign sticker, pen, bag or similar of a political party, and (6) signing a petition in the street (see Knoll et al. 2020; Valentino et al. 2011). 


\section{Moderators}

The measure for personal curation skills $(\alpha=.94, M=4.24, \mathrm{SD}=1.95)$ was derived from the conceptualization of access as a main capability of media literacy (Aufderheide 1993; Buckingham 2007). The items asked participants whether they agreed that they (1) have control over the content which is displayed on their SM newsfeed, (2) can change the content which they see on their newsfeed anytime, and (3) know how to adjust their newsfeed so that they see the information they are interested in the most. We measured participants' social media political exposure $(\alpha=.76$, $M=3.37, S D=1.59)$ as how often $(1=$ never, $7=$ often $)$ participants encounter political posts from (1) friends, (2) media organizations and (3) political actors in their newsfeed.

\section{Control variables}

We measured political interest (Spearman-Brown coefficient $\left(\rho_{(t 1)}\right)=0.92, M=4.90$, $\mathrm{SD}=1.81)$ with two items asking how much respondents were interested $(1=$ not interested, $7=$ very interested) in (a) politics and (b) the current election. Measured for political efficacy $(\alpha=0.91, M=4.85, \mathrm{SD}=1.68)$ built on Niemi et al. (1991). The items asked respondents whether they agreed that they (1) feel competent enough to participate in political decision-making processes, (2) are at least as well informed about politics compared to other people, (3) have a good understanding of political issues in Austria. Political trust $(\alpha=0.93, M=2.33, \mathrm{SD}=1.26)$ was measured with three items obtained from Craig et al. (1990), asking respondents whether they agree that (1) politicians in Austria keep what they promise to the people, (2) they can trust Austrian politicians to make decisions which are in the interest of the people, and (3) politicians in Austria are honest to the people.

\section{Statistical analysis}

We used R for hypothesis testing. Data and analysis scripts are available online (osf. io/vqb7f/). We ran ordinary least squares (OLS) to predict scores of incidental and intentional exposure modes. To predict low- and high-effort participation, we use count models. To predict low-effort participation, we ran Poisson regression, the standard model to estimate count responses. Furthermore, we used negative binomial regression to predict high-effort participation, since this variable showed signs of overdispersion (Hilbe 2011).

Since we collected data at two points in time, we use regression analysis with lagged dependent variables, in which we predict the dependent variables at time 2 and control for the lagged score of the dependent variable at time 1 (autoregressive effect). All independent variable were measured at time 1. With these models, we predict changes in the dependent variable from time 1 to time 2 . As compared to cross-sectional analysis, this approach has several advantages. Most importantly, it reduces problems associated with sample bias and reversed causation, because 
changes in the dependent variable from time 1 to time 2 cannot affect measures at time 1 (Prior 2005). However, despite these advantages, our data remain selfreported and may still suffer from confounders.

Even though conceptually we follow a mediation logic, we cannot test for indirect effects explicitly because we have two-wave panel data at hand. We did not calculate indirect effects because it would require us to replace the panel logic (autoregressive model) in one model with a cross-sectional logic. This would make our results less informative regarding causality.

Variance inflation factors for all predictor variables in Model 1 and Model 2 of Table 1 and Model 1 and Model 2 of Table 2 were below 2.7 and were, thus, not concerning.

\section{Results}

Table 1 shows the results for H1-H4. We also employed a set of conventional control variables which assess individuals' political involvement (interest, trust and efficacy). Model 2 shows that the informational motivation significantly predicted the intentional mode $(b=0.10, p=.013)$. Hence, our data lend support for H1. H2 suggested that the effect of political information motivation would be boosted by high levels of personal curation skills. Model 3 in Table 1 indeed indicates a significant interaction effect which points in the expected direction $(b=0.03, p=.041)$. Figure 1 visualizes the effect of political information motivation conditional on different levels of personal curation skills (see Hayes and Matthes 2009). The effect is significant when personal curation skills are higher than 4.27 (on the 7-point scale). Hence, our data support H2. H3 suggested that the effect of political information motivation on the intentional exposure mode would also increase with social media political exposure. Model 4 in Table 1 shows that the interaction is not significant $(b=0.04$, $p=.067)$. Thus, $\mathrm{H} 3$ is rejected.

It should be noted that our finding for $\mathrm{H} 2$ may not be fully robust. When we run models with all eight interactions for personal curation skills and social media political exposure, the interaction term of political motivation times skills, though still pointing in the expected direction, becomes slightly weaker and insignificant. There is reason to assume that the interaction with skills and political exposure may explain similar parts of the variance in our dependent variable and that our sample is too small to detect significant effects in such a complex model. We discuss the lack of robustness of our results in the limitation section.

Model 1 in Table 1 shows the results for incidental mode of exposure. The results provide strong evidence that political information motivation is negatively related to the incidental mode $(b=-0.18, p<.001)$. H4 suggested that non-political motivations would lead to the incidental exposure mode. We find robust support that entertainment motivation is highly significantly and positively related to the incidental mode (H4a, $b=0.17, p<.001)$. Although we find a positive coefficient for social interaction motivation, it is not statistically significant $(\mathrm{H} 4 \mathrm{~b}, b=0.10, p=.060)$. Similarly, we did not find a significant effect of expressive motivation $(\mathrm{H} 4 \mathrm{c}, b=0.05$, $p=.550)$. 
Table 1 OLS regressions predicting the incidental and intentional mode of exposure

\begin{tabular}{|c|c|c|c|c|}
\hline & $\begin{array}{l}\text { Incidental } \\
\text { Mode (W2) }\end{array}$ & $\begin{array}{l}\text { Intentional } \\
\text { Mode (W2) }\end{array}$ & $\begin{array}{l}\text { Intentional } \\
\text { Mode (W2) }\end{array}$ & $\begin{array}{l}\text { Intentional } \\
\text { Mode (W2) }\end{array}$ \\
\hline & Model 1 & Model 2 & Model 3 & Model 4 \\
\hline & $b(\mathrm{SE})$ & $b(\mathrm{SE})$ & $b(\mathrm{SE})$ & $b(\mathrm{SE})$ \\
\hline \multicolumn{5}{|l|}{ Motivations } \\
\hline Mot: political info (POL) & $-0.18 * * *(0.05)$ & $0.10 *(0.04)$ & $-0.07(0.09)$ & $-0.04(0.08)$ \\
\hline Mot: entertainment (ENT) & $0.17 * * *(0.05)$ & $-0.05(0.04)$ & $0.03(0.08)$ & $0.01(0.07)$ \\
\hline Mot: self-expression (EXP) & $-0.04(0.06)$ & $0.04(0.04)$ & $0.01(0.12)$ & $0.09(0.11)$ \\
\hline Mot: social use (SOC) & $0.10^{+}(0.05)$ & $0.04(0.04)$ & $0.12(0.09)$ & $0.03(0.09)$ \\
\hline \multicolumn{5}{|l|}{ Moderators } \\
\hline $\begin{array}{l}\text { Personal curation skills } \\
\quad(\mathrm{PCS})\end{array}$ & $0.08 *(0.04)$ & $-0.001(0.03)$ & $0.03(0.06)$ & $0.0002(0.03)$ \\
\hline $\begin{array}{l}\text { Social media political expo- } \\
\text { sure (SMPEX) }\end{array}$ & $0.07(0.05)$ & $0.03(0.04)$ & $0.03(0.04)$ & $0.04(0.09)$ \\
\hline \multicolumn{5}{|l|}{ Interactions } \\
\hline $\mathrm{POL} * \mathrm{PCS}$ & & & $0.03 *(0.02)$ & \\
\hline $\mathrm{ENT} * \mathrm{PCS}$ & & & $-0.02(0.02)$ & \\
\hline $\mathrm{EXP} * \mathrm{PCS}$ & & & $0.005(0.02)$ & \\
\hline SOC * PCS & & & $-0.02(0.02)$ & \\
\hline POL * SMPEX & & & & $0.04^{+}(0.02)$ \\
\hline ENT * SMPEX & & & & $-0.02(0.02)$ \\
\hline EXP * SMPEX & & & & $-0.01(0.03)$ \\
\hline SOC * SMPEX & & & & $0.001(0.02)$ \\
\hline \multicolumn{5}{|l|}{ Control variables } \\
\hline Age & $0.001(0.01)$ & $-0.01 *(0.004)$ & $-0.01 *(0.004)$ & $-0.01 * *(0.004)$ \\
\hline Female & $0.04(0.14)$ & $-0.02(0.10)$ & $-0.02(0.10)$ & $-0.03(0.10)$ \\
\hline Medium education (vs. low) & $-0.13(0.16)$ & $-0.05(0.11)$ & $-0.07(0.11)$ & $-0.05(0.11)$ \\
\hline High education (vs. low) & $-0.27(0.18)$ & $0.13(0.13)$ & $0.12(0.13)$ & $0.10(0.13)$ \\
\hline Political interest & $-0.03(0.06)$ & $-0.003(0.04)$ & $-0.01(0.04)$ & $0.005(0.04)$ \\
\hline Political trust & $-0.13^{*}(0.05)$ & $0.06(0.04)$ & $0.06^{+}(0.04)$ & $0.06(0.04)$ \\
\hline Political efficacy & $0.06(0.06)$ & $0.03(0.04)$ & $0.02(0.04)$ & $0.03(0.04)$ \\
\hline \multicolumn{5}{|l|}{ Autoregressive effects } \\
\hline Incidental mode (W1) & $0.46 * * *(0.04)$ & & & \\
\hline Intentional mode (W1) & & $0.59 * * *(0.04)$ & $0.59 * * *(0.04)$ & $0.57 * * *(0.04)$ \\
\hline Constant & $1.20 * *(0.41)$ & $0.55^{+}(0.29)$ & $0.48(0.37)$ & $0.58(0.37)$ \\
\hline$R^{2}$ & 0.35 & 0.55 & 0.56 & 0.56 \\
\hline
\end{tabular}

Note: Cell entries show OLS regression coefficients with standard error in parentheses, $n=559$ ${ }^{+} p<0.1 ; * p<0.05 ; * * p<0.01 ; * * * p<0.001$ (two-tailed)

In Table 2, we proceed to explain high- and low-effort political participation. We use the same predictors as in the previous model, but now add the intentional and incidental mode variables to our model. A quick look at the effects of the intentional and incidental mode on both low- and high-effort participation indicates that only the intentional 
Table 2 Effects of the incidental and intentional mode of exposure on low-effort participation (Poisson regression) and high-effort participation (negative binomial regression)

\begin{tabular}{|c|c|c|}
\hline & $\begin{array}{l}\text { Low-effort } \\
\text { Participation (W2) }\end{array}$ & $\begin{array}{l}\text { High-effort } \\
\text { Participation (W2) }\end{array}$ \\
\hline & Model 1 & Model 2 \\
\hline & $b(\mathrm{SE})$ & $b(\mathrm{SE})$ \\
\hline \multicolumn{3}{|l|}{ Exposure mode } \\
\hline Intentional mode & $0.10 * *(0.03)$ & $0.01(0.07)$ \\
\hline Incidental mode & $0.03(0.03)$ & $0.01(0.05)$ \\
\hline \multicolumn{3}{|l|}{ Motivations } \\
\hline Mot: political info (POL) & $-0.02(0.03)$ & $0.12^{+}(0.07)$ \\
\hline Mot: entertainment (ENT) & $0.04(0.03)$ & $-0.06(0.07)$ \\
\hline Mot: self-expression (EXP) & $0.003(0.03)$ & $0.06(0.07)$ \\
\hline Mot: social use (SOC) & $0.04(0.03)$ & $0.01(0.07)$ \\
\hline \multicolumn{3}{|l|}{ Control variables } \\
\hline Age & $-0.003(0.003)$ & $-0.01(0.01)$ \\
\hline Female & $-0.08(0.08)$ & $-0.60 * * *(0.18)$ \\
\hline Medium education (vs. low) & $0.06(0.09)$ & $-0.22(0.20)$ \\
\hline High education (vs. low) & $0.14(0.10)$ & $-0.05(0.22)$ \\
\hline Political interest & $0.05(0.04)$ & $0.03(0.08)$ \\
\hline Political trust & $-0.09 * *(0.03)$ & $-0.04(0.07)$ \\
\hline Political efficacy & $0.09 *(0.04)$ & $0.02(0.08)$ \\
\hline \multicolumn{3}{|l|}{ Autoregressive effects } \\
\hline LE participation (W1) & $0.30 * * *(0.03)$ & $0.25 * * *(0.06)$ \\
\hline HE participation (W1) & $0.05(0.03)$ & $0.44 * * *(0.07)$ \\
\hline Constant & $-1.43 * * *(0.27)$ & $-1.79 * *(0.55)$ \\
\hline Log likelihood & -730.98 & -416.20 \\
\hline$\theta$ & & $1.31 * * *(0.34)$ \\
\hline
\end{tabular}

Cell entries show Poisson regression and negative binomial regression coefficients with standard error in parentheses, $n=559$

${ }^{+} p<0.1 ; * p<0.05 ; * * p<0.01 ; * * * p<0.001$ (two-tailed)

mode of exposure significantly predicted low-effort participation $(b=0.10, p=.001)$. However, we did not find an effect on high-effort participation and the incidental mode did not exert any significant effects. We thus only find support for H5b while H5a and H6 were rejected.

The results also indicate that individuals with high political information motivation scored higher on high-effort participation. Furthermore, political trust was negatively and political efficacy positively related to low-effort participation. 
Fig. 1 Effect of political information motivation on the intentional mode of exposure on SM conditional on different levels of personal curation skills. Effects based on Table 1. Shaded region represents $95 \%$ confidence intervals

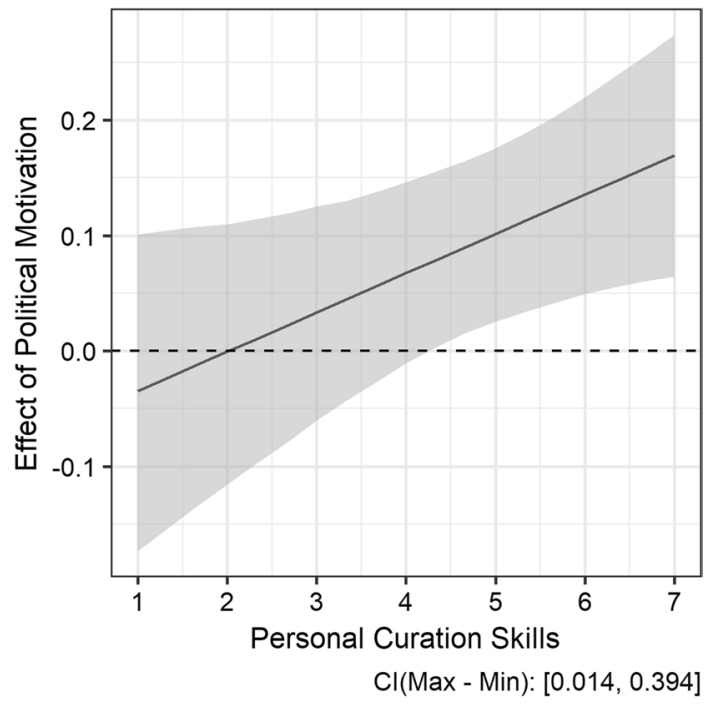

\section{Discussion}

This study advances our knowledge about the modes in which SM users are exposed to political content. We illustrated how motivations influence the mode in which users encounter political information. As expected, the results of our panel study showed that individuals who use SM for political information motivations were more likely to encounter political information in the intentional mode. Furthermore, this effect was stronger for SM users who reported to have higher levels of personal curation skills-although this finding may not be fully robust. This tells us that the level to which users can follow their political motivations on SM is contingent on their skills to customize their SM experience. In that sense, SM may particularly resemble a high-choice media environment for individuals that have the skills and knowledge to pick the content they want to see. We did not find such a pattern for individuals with more robust political exposure in their network.

Turning to the driving motivations for people to encounter political information on SM in the incidental mode, we found mixed results. We expected that users who turn to SM to gratify non-political motivations are more likely to stumble upon political information in the incidental mode. While the results suggest that this is true for entertainment motivations, we did not find an effect for self-expression motivations and social interaction motives.

Besides explaining why people are exposed to political information on SM in the incidental or the intentional mode, the second main objective of this study was to explain effects of the two exposure modes on political participation. In contrast to most studies in the field, we relied on a distinction between high- and low-effort participation rather than an online and offline dichotomy.

Interestingly, the intentional mode of exposure to political information on SM positively predicted low-effort participation but not high-effort participation. In 
other words, seeking political information actively on SM does have a positive effect on future political participation, but this effect only occurs for participatory activities that are relatively low cost and risk. Although this result might dash hope in SM as reviver of political participation, we want to point out that our data indicated that low-effort participation may in turn increase high-effort participation (see Model 2 in Table 2; see Vaccari et al. 2015).

However, we did not find an effect of the incidental exposure mode on political participation. Against our expectations, the incidental mode did not instigate low-effort participation. This finding is contrary to previous cross-sectional studies which have suggested that mere incidental exposure to political information on SM can foster political participation (e.g., Valeriani and Vaccari 2016). In contrast to other studies relying on cross-sectional data, we turn to autoregressive models which allow us to probe our hypotheses more strictly. Our null result, once again, might highlight the importance of processing when it comes to effects of political information. With processing being dependent on motivational factors, individuals in the incidental mode might not be in the mindset to process political information effortfully. Although the SMPPM argues that incidental exposure can have effects, it also stresses that one should only expect very limited effects (e.g., via goal priming, see Knoll et al. 2020).

One may conclude that the effects found in this study are rather small if common guidelines for interpreting the size of effects sizes are applied. However, it has been argued that seemingly small effects sizes may still be meaningful when predicting changes in the dependent variables from T1 to T2 while controlling for values of the dependent in T1 (i.e., controlling for stability effects, Adachi and Willoughby 2015). For example, according to common guidelines, the effect of the intentional mode on low-effort political participation is with $b=0.10$ rather small. Given that the bivariate correlation for low-effort political participation at T1 and low-effort political participation at T2 is rather large $(r=0.66)$ and the concurrent correlation between low-effort political participation at $\mathrm{T} 1$ and the intentional mode at $\mathrm{T} 1$ is also of substantial size $(r=0.51)$, the effect should not be dismissed as meaningless (Adachi and Willoughby 2015). Clearly, the interaction effect signaling that highly skilled individuals are more likely to transform the political motivations into the intentional mode is substantially smaller $(b=0.03)$. Thus, future research investigating whether such effects accumulate over time is needed.

This study has some limitations. First, similar to other studies in this field, we discuss the importance of elaboration and processing of political information to have an impact on political participation but we do not directly measure the concept of information elaboration. Unfortunately, it is hardly possible to measure this adequately in survey: we assume that citizens use social media for various motivations-political and non-political needs-, therefore, we would need an elaboration measure for both types of political information encounters-incidental and intentional. Second, the data collection was conducted during an election period. Attention to political information, political behavior, and participation patterns might differ during election campaigns. Therefore, future studies should investigate similar effects in non-election years. Third, we rely on self-report data for exposure (see Scharkow 2019). The chance of memory bias should be considered while findings regarding the social media political exposure 
variable are interpreted (see Naab et al. 2019; Schnauber-Stockmann and Karnowski 2020). Specifically, politically motivated individuals might be more likely to recall political information encounters than their non-motivated counterparts. Fourth, our sample size is rather small for the complex autoregressive models we calculated. Thus, results for the interaction hypothesis with personal curation skills are not fully robust. Replication with larger samples is needed. Also, our theory implies a mediation logic. However, due to being restricted to two waves we were not able to test this assumption formally. Future studies should test the mediation effect formally by collecting data for more than two points in time. Finally, future research should distinguish the dimensions of incidental exposure more carefully, i.e., the passive scanning of incidentally encountered political information and the intentional processing of incidentally encountered content appraised as relevant (Matthes et al. 2020).

Despite these limitations, this study's contribution to the current body of research is threefold. First, we relied on a measurement that is less likely to conflate the incidental and intentional mode of exposure. Earlier studies often relied on one-item measures (Tewksbury et al. 2001), which might not accurately distinguish between the two modes of exposure. Assumed that the two modes are subsequently related to different cognitive strategies a clear-cut distinction is crucial to sort out the possibly diverging effects.

Second, this paper improves our theoretical understanding of the motivations, which drive people to be in the incidental or intentional mode of exposure on SM. Non-political and political motivations clearly have distinctive effects on the mode in which users encounter political information. This, once again, underlines the importance of motivations when considering effects of SM. However, although we investigated the effects of three of the most important non-political motivations (i.e., social interaction, self-expression and entertainment), other motivations like pass time could also be driving forces behind SM usage and might create distinctive effects. Furthermore, different motivations might also lead individuals to turn to different features of SM (e.g., search function or newsfeed, see Leiner et al. 2018). These functional domains of SM platforms can shape the opportunities of individuals to encounter political information. In other words, even though the tendency to process political information effortfully should be rather low for all non-political needs, pursuing some non-political motivations might provide individuals with more opportunities to encounter political information incidentally than others. For instance, an individual that scans his or her newsfeed because of past time motivations might have more opportunities to be incidental exposed than an individual that uses the chat function to gratify social interaction motivations. Although both are in the incidental mode and might be hardly inclined to process political information effortfully, one might have more opportunities for incidental exposure.

Third, to some extent our results cast doubt whether mere incidental exposure to political information really drives less engaged individuals into political participation. According to the SMPPM, exposure to political information only leads to effortful processing when the content is appraised as relevant. But while being in the incidental mode, one is less likely to perceive political information as relevant because it most likely does not match with currently more dominant non-political motivations. Still, there might be some situations in which political information is appraised as relevant by individuals in the incidental mode (e.g., a strong partisan might be triggered by partisan or ideological cues; individual's domain-specific 
personal interest in a topic) and might subsequently lead to participation. In a similar vein, our results support the idea that processing and elaboration of political information are important intermediaries between being exposed to political information and engaging in politics (e.g., McLeod et al. 1999). However, we suggest future studies to probe this relationship more thoroughly (see Knoll et al. 2020). Implementing experimental designs should allow scholars to follow cognitive tasks more closely than self-reported survey data.

Funding Open access funding provided by Austrian Science Fund (FWF). This research was supported by the Austrian Science Fund (FWF), project P 31081-G29.

\section{Compliance with ethical standards}

Conflict of interest On behalf of all authors, the corresponding author states that there is no conflict of interest.

Open Access This article is licensed under a Creative Commons Attribution 4.0 International License, which permits use, sharing, adaptation, distribution and reproduction in any medium or format, as long as you give appropriate credit to the original author(s) and the source, provide a link to the Creative Commons licence, and indicate if changes were made. The images or other third party material in this article are included in the article's Creative Commons licence, unless indicated otherwise in a credit line to the material. If material is not included in the article's Creative Commons licence and your intended use is not permitted by statutory regulation or exceeds the permitted use, you will need to obtain permission directly from the copyright holder. To view a copy of this licence, visit http://creativecommons.org/licenses/by/4.0/.

\section{References}

Adachi, P., and T. Willoughby. 2015. Interpreting effect sizes when controlling for stability effects in longitudinal autoregressive models: implications for psychological science. European Journal of Developmental Psychology 12 (1): 116-128.

Ancu, M., and R. Cozma. 2009. MySpace politics: Uses and gratifications of befriending candidates. Journal of Broadcasting \& Electronic Media 53 (4): 567-583.

Aufderheide, P. 1993. Media literacy: A report of the National Leadership Conference on Media Literacy. Aspen, CO: Aspen Institute.

Baek, K., A. Holton, D. Harp, and C. Yaschur. 2011. The links that bind: Uncovering novel motivations for linking on Facebook. Computers in Human Behavior 27 (6): 2243-2248.

Beam, M.A., J.D. Hmielowski, and M.J. Hutchens. 2018. Democratic digital inequalities: Threat and opportunity in online citizenship from motivation and ability. American Behavioral Scientist 62 (8): 1079-1096.

Blankenship, K.L., and D.T. Wegener. 2008. Opening the mind to close it: Considering a message in light of important values increases message processing and later resistance to change. Journal of Personality and Social Psychology 94 (2): 196-213.

Bode, L. 2016. Political news in the news feed: Learning politics from social media. Mass Communication and Society 19 (1): 24-48.

Brady, H.E. 1999. Political participation. In Measures of political attitudes, vol. 2, ed. J.P. Robinson, P.R. Shaver, and L.S. Wrightsman, 737-801. San Diego, CA: Academic Press.

Buckingham, D. 2007. Digital media literacies: Rethinking media education in the age of the internet. Research in Comparative and International Education 2 (1): 43-55.

Carpenter, S. 2018. Ten Steps in Scale Development and Reporting: A Guide for Researchers. Communication Methods and Measures 12 (1): 25-44. 
Cho, J., S. Ahmed, H. Keum, Y.J. Choi, and J.H. Lee. 2018. Influencing myself: Self-Reinforcement through online political expression. Communication Research 45 (1): 83-111.

Correa, T. 2016. Digital skills and social media use: How internet skills are related to different types of Facebook use among 'digital natives'. Information, Communication \& Society 19 (8): $1095-1107$.

Craig, S.C., R.G. Niemi, and G.E. Silver. 1990. Political efficacy and trust: A report on the NES pilot study items. Political Behavior 12 (3): 289-314.

Fletcher, R., and R.K. Nielsen. 2018. Are people incidentally exposed to news on social media? A comparative analysis. New Media \& Society 20 (7): 2450-2468.

Gerodimos, R. 2008. Mobilising young citzens in the UK: A content analysis of youth and issue websites. Information, Communication \& Society 11 (7): 964-988.

Gibson, R., and M. Cantijoch. 2013. Conceptualizing and measuring participation in the age of the Internet: Is online political engagement really different to offline? The Journal of Politics 75 (3): 701-716.

Gil de Zúñiga, H., L. Molyneux, and P. Zheng. 2014. Social media, political expression, and political participation: Panel analysis of lagged and concurrent relationships. Journal of Communication 64 (4): 612-634

Hayes, A.F., and J. Matthes. 2009. Computational procedures for probing interactions in OLS and logistic regression: SPSS and SAS implementations. Behavior Research Methods 41 (3): 924-936.

Heiss, R., J. Knoll, and J. Matthes. 2019. Pathways to political (dis-)engagement: motivations behind social media use and the role of incidental and intentional exposure modes in adolescents' political engagement. Communications. https://doi.org/10.1515/commun-2019-2054.

Heiss, R., and J. Matthes. 2016. Mobilizing for some: The effects of politicians' participatory Facebook posts on young people's political efficacy. Journal of Media Psychology 28 (3): 123-135.

Heiss, R., and J. Matthes. 2019. Does incidental exposure on social media equalize or reinforce participatory gaps? Evidence from a panel study. New Media \& Society 21 (11-12): 2463-2482.

Hilbe, J.M. 2011. Negative binomial regression. Cambridge, UK: Cambridge University Press.

Johann, D. 2012. Specific political knowledge and citizens' participation: Evidence from Germany. Acta Politica 47 (1): 42-66.

Kaye, B.K., and T.J. Johnson. 2004. A Web for all reasons: Uses and gratifications of Internet components for political information. Telematics and Informatics 21 (3): 197-223.

Knoll, J., J. Matthes, and R. Heiss. 2020. The social media political participation model: A goal systems theory perspective. Convergence: The International Journal of Research into New Media Technologies 26 (1): 135-156.

Kruglanski, A.W., J.Y. Shah, A. Fishbach, R. Friedman, W.Y. Chun, and D. Sleeth-Keppler. 2002. A theory of goal systems. In Advances in experimental social psychology, vol. 34, ed. M.P. Zanna, 331-378. San Diego, CA: Academic Press.

Krugman, H.E., and E.L. Hartley. 1970. Passive learning from television. Public Opinion Quarterly 34 (2): 184-190.

Leiner, D.J., L. Kobilke, C. Rueß, and H.-B. Brosius. 2018. Functional domains of social media platforms: Structuring the uses of Facebook to better understand its gratifications. Computers in Human Behavior 83: 194-203.

Matthes, J., A. Nanz, M. Stubenvoll, and R. Heiss. 2020. Processing news on social media. The political incidental news exposure model (PINE). Journalism 21 (8): 1031-1048.

McLeod, J.M., D.A. Scheufele, and P. Moy. 1999. Community, communication, and participation: The role of mass media and interpersonal discussion in local political participation. Political Communication 16 (3): 315-336.

Naab, T.K., V. Karnowski, and D. Schlütz. 2019. Reporting Mobile Social Media Use: How Survey and Experience Sampling Measures Differ. Communication Methods and Measures 13 (2): 126-147.

Niemi, R.G., S.C. Craig, and F. Mattei. 1991. Measuring internal political efficacy in the 1988 National Election Study. The American Political Science Review 85 (4): 1407.

Oeldorf-Hirsch, A. 2018. The role of engagement in learning from active and incidental news exposure on social media. Mass Communication and Society 21 (2): 225-247.

Oser, J., M. Hooghe, and S. Marien. 2013. Is online participation distinct from offline participation? A latent class analysis of participation types and their stratification. Political Research Quarterly 66 (1): 91-101.

Palmgreen, P. 1984. Uses and gratifications: A theoretical perspective. Annals of the International Communication Association 8 (1): 20-55. 
Pew Research Center. 2018. Many Facebook users don't understand its news feed. 5 September. https ://www.pewresearch.org/fact-tank/2018/09/05/many-facebook-users-dont-understand-how-the-sites -news-feed-works/. Accessed 30 Oct 2018.

Prior, M. 2005. News vs. entertainment: How increasing media choice widens gaps in political knowledge and turnout. American Journal of Political Science 49 (3): 577-592.

Ruggiero, T.E. 2000. Uses and gratifications theory in the 21 st century. Mass Communication and Society 3 (1): 3-37.

Scharkow, M. 2019. The Reliability and Temporal Stability of Self-reported Media Exposure: A Metaanalysis. Communication Methods and Measures 13 (3): 198-211.

Schnauber-Stockmann, A., and V. Karnowski. 2020. Mobile Devices as Tools for Media and Communication Research: A Scoping Review on Collecting Self-report Data in Repeated Measurement Designs. Communication Methods and Measures 14 (3): 145-164.

Skoric, M.M., Q. Zhu, D. Goh, and N. Pang. 2016. Social media and citizen engagement: A meta-analytic review. New Media \& Society 18 (9): 1817-1839.

Tang, G., and F.L.F. Lee. 2013. Facebook use and political participation: The impact of exposure to shared political information, connections with public political actors, and network structural heterogeneity. Social Science Computer Review 31 (6): 763-773.

Tewksbury, D., A.J. Weaver, and B.D. Maddex. 2001. Accidentally informed: Incidental news exposure on the world wide web. Journalism \& Mass Communication Quarterly 78 (3): 533-554.

Thorson, K., and C. Wells. 2016. Curated flows: A framework for mapping media exposure in the digital age. Communication Theory 26 (3): 309-328.

Vaccari, C., A. Valeriani, P. Barberá, R. Bonneau, J.T. Jost, J. Nagler, and J.A. Tucker. 2015. Political expression and action on social media: Exploring the relationship between lower- and higher-threshold political activities among Twitter users in Italy. Journal of Computer-Mediated Communication 20 (2): 221-239.

Valentino, N.A., T. Brader, E.W. Groenendyk, K. Gregorowicz, and V.L. Hutchings. 2011. Election night's alright for fighting: The role of emotions in political participation. The Journal of Politics 73 (1): 156-170.

Valeriani, A., and C. Vaccari. 2016. Accidental exposure to politics on social media as online participation equalizer in Germany, Italy, and the United Kingdom. New Media \& Society 18 (9): 1857-1874.

Van Aelst, P., J. Strömbäck, T. Aalberg, F. Esser, C. de Vreese, J. Matthes, et al. 2017. Political communication in a high-choice media environment: A challenge for democracy? Annals of the International Communication Association 41 (1): 3-27.

Weeks, B.E., D.S. Lane, D.H. Kim, S.S. Lee, and N. Kwak. 2017. Incidental exposure, selective exposure, and political information sharing: Integrating online exposure patterns and expression on social media. Journal of Computer-Mediated Communication 22 (6): 363-379.

Worthington, R.L., and T.A. Whittaker. 2006. Scale development research: A content analysis and recommendations for best practices. The Counseling Psychologist 34 (6): 806-838.

Publisher's Note Springer Nature remains neutral with regard to jurisdictional claims in published maps and institutional affiliations.

Andreas Nanz (MA, University of Vienna) is Ph.D. candidate at the University of Vienna. His research interests include information processing and political behavior in digital media.

Raffael Heiss (Ph.D., University of Vienna) is postdoctoral researcher at the MCI Management Center Innsbruck. His research interests include digital media use, information processing, and civic participation. He has co-authored the Social Media Political Participation Model.

Jörg Matthes (Ph.D., University of Zurich) is professor of communication science at the University of Vienna. His research interests include political communication, digital media use, media effects, and advertising. He has co-authored the Social Media Political Participation Model. 